\title{
An Application Of Analytic Network Process (ANP) To Evaluate Green Supply Chain Management Strategies: A Case Study
}

\author{
Arvind Jayant ${ }^{1}$ \\ Mechanical Engineering Department, \\ SLIET Deemed University, Longowal, Sangrur, Punjab, India \\ (Deemed University under MHRD, Govt. of India)
}

\begin{abstract}
Sustainable development has made remarkable progress in establishing environmental and social sustainability towards operations management and the supply chain. Sustainable development means "Development that meets the needs of the present without compromising the ability of future generations" Sustainability covers three aspects: economic, environmental and social responsibility. Green supply chain management (GSCM) is about making the entire supply chain more environmental sustainable. With the raising of awareness in environmental protection and sustainable development in enterprises, the green issue has become more and more critical in supply chain management. The green supply chain strategy selection is a multi-criterion problem which includes both qualitative and quantitative criteria. ANP is a multi-attribute, decision-making approach based on the reasoning, knowledge, and experience of the experts in the field. ANP can act as a valuable aid for decision making the best decision when both qualitative and quantitative aspects of decision are considered. ANP provides a general framework to deal with decisions without making assumptions about the independence of higher-level elements from lower level elements and about the independence of the elements within a level. The present work proposes a structured model for evaluating and selecting a Green Supply Chain Strategy by using Analytical Network Process (ANP) approach. The model is developed using evidence from empirical study in the industry. The model for selection of green supply chain strategy includes considers both the practicality in traditional SCM selection criteria, and also the green concept related to environmental protection and regulations. The proposed ANP model is used to evaluate the green supply chain strategy in Indian Automotive Company XYZ Ltd. The major advantages of this research are that it can be used for both qualitative and quantitative criteria. The results show that the model has the capability to be flexible and apply in different types of industries to choose their green supply chain strategy. The future research directions to this work include the design of more complex hierarchies and explore it. It may benefit the Indian industries to survive and serve better in Global Markets.
\end{abstract}

\section{Introduction}

With increasing government regulation and stronger public awareness in environmental protection, firms today simply cannot ignore environmental issues if they want to survive in the global market. In addition to complying with the environmental regulations for selling products in certain countries, firms need to implement strategies to voluntarily reduce the environmental impacts of their products. The integration of environment, economic and social performances to achieve sustainable development is a major business challenge for the new century [20].Green Supply Chain Management (GSCM) adds 'green' component to the conventional supply chains by including practices like green operations, green design, green manufacturing, reverse logistics and waste management [18].GSCM has been gaining much attention of academia and industry over the last few years. The companies cannot afford to ignore environmental issues in today's competitive business environment. Increasing government regulations and stronger public mandates for environmental accountability have brought the green issues high on the strategic planning agenda of manufacturing firms [21].GSCM practices have become a very important part of company's policy and are increasingly turning into a major strategic thrust in business organizations. GSCM is a relatively new concept for the majority of Indian automobile firms.

Decision making in supply chain is crucial as it involves multi-criteria, multi- level, multi-objective and multipersonal decisions. The emphasis on higher co-operation and co-ordination among the partners of supply chain is key issue, which requires strategies suitable to systemoptimal performance where the point of focus shifts from local to global optimal. Some of the factors are tangible and general in nature, while some other are situation specific and intangible in nature. Multi-criteria decision making tools like AHP and ANP are gaining wide

Arvind Jayant: arvindjayant@gmail.com 
applicability and attempt has been made to make use of them in issues related to inbound supply chain. The priority coefficients thus found by these techniques are used in optimization techniques to get desired results. Application of supply chain concepts has been made in service industry as no such work has been attempted earlier.

Strategic planning in GSCM context means the identification of relevant goals and specification of long term plans for managing those goals [13].It charts out the future course of action for GSCM implementation. The biggest challenge in GSCM practices for companies is to select suitable strategies in accordance with the stipulated regulations and customers requirements [6]. Several studies have emphasized on developing GSCM strategies from an overall organizational perspective.

There are many approaches to evaluating performance indices system, such as linear weighting methods [5], data envelopment analysis, analytic hierarchy process (AHP) [22], total cost approaches [10], and mathematical programming techniques [3]. AHP is a relatively popular tool for modelling strategic decisions, but a primary limitation is its basic relationships do not allow for an integrated dynamic modelling of the environment. AHP assumes the system elements are uncorrelated and are unidirectional introduced by a hierarchical relationship. A more general evaluation approach defined as the analytical network process (ANP), or systems withfeedback approach, may be used to evaluate a dynamic multi-directional relationship among decision attributes. ANP allows for more complex interrelationships among the decision levels and attributes. ANP does not require this strictly hierarchical structure. Interdependencies may be represented by two way arrows (or arcs) among levels, or if within the same level of analysis, a looped arc. The directions of the arcs signify dependence, arcs emanate from an attribute to other attributes that may influence it. The relative importance or strength of the impacts on a given element is measured on a ratio scale similar to AHP. The ANP approach is capable of handling interdependence among elements by obtaining the composite weights through the development of a 'super matrix'. Saaty explains the super matrix concept as a parallel to the Markov chain process [8]. However, in real-life decision-making situation, decision-makers could be uncertain about their own level of preference, due to incomplete information or knowledge, complexity and uncertainty within the decision environment. Such situation may occur when evaluating SCM performance indices system. In SCM performance evaluation problem, decision-makers might intuitively feel that some factors are more important that others in affecting their final preference among alternatives. If there is some feedback and interdependency among the factors, an unimportant factor may turn out to be far more important than even the most intuitively important one. Therefore, a fuzzy ANP approach is proposed to handle SCM performance evaluation problem.
The study aims to provide a guideline for the electronic industry on how to choose an appropriate GSCM strategy, which incorporates environmental perception with corporate functional strategies in order to achieve an effective green management. The integration of environmental corporate strategy with every corporate functional strategy will facilitate the connections between each functional strategy and thereby eliminate obstacles to environmental integration. Due to the fact that many companies have just started exploring environmental concerns in the recent years, a lot of environmental related factors have not yet been identified systematically.

The rest of this paper is organized as follows. Section 2 discusses literature reviews from different authors and methodology for selection of strategies in GSCM in context of various companies. Next, Section 3 debates the ANP approach. Section 4 then presents an illustrative case study which used for strategy selection using the ANP model. Finally, Section 5 presents procedure and result and section 6 presents conclusions and limitations.

\section{GSCM strategy}

No matter green manufacturing strategies or environmental strategies, past studied discussed and classified them mostly according to attitudes that companies held toward to green management, the simplest is divided into proactive and reactive. Besides, GSCM related researches also examined the enhancement and implications of GSCM practices, and GSCM performance evaluations. In order to foster the future development of GSCM activities, some GSCM strategies based on classical SCM theories were proposed. These four GSCM strategies as listed below [17].

(1) risk-based strategy: companies choosing this kind of GSCM strategy most invested minimal resources of organization for green management, and also asked their suppliers to comply the environmental requirements for reducing risks. Although some international environmental rules are difficult to refer to, it is the simplest GSCM strategy compared to other types. Therefore, companies couldn't create unique competitive advantage, and then didn't' obtain many economic benefits from this strategy. Also, these companies didn't spontaneously introduce environmental programs; it is not possible to expect any innovation happened. The final goal of this type of strategy is risk minimization with accomplishing environmental programs passively.

(2) efficiency-based strategy: compared the above one, this type of strategy is more complicated owing to efficiency improving through specific approaches. It not only facilitated companies to allow increase economic benefits, but also won the environmental benefits resulted from waste reduction and resources used efficiently. However the efficiency-based strategy still aimed more on increasing productivity, it is impossible to avoid from any toxic or harmful substances during production processes completely. Hence, the environmental 
programs in this type of strategy primary directed firms to reduce cost and meet the Operational optimization, and decrease environmental depredations at the same time. But the efficiency based strategy still didn't create any proactive plans or activities, such as innovative technologies or approaches in environmental protection.

(3) innovation-based strategy: this type of strategy guided companies to develop products from product life-cycle viewpoints, and give stricter environmental requirements to their suppliers, and even train them to adjust operational processes just followed the newest environmental regulations. The companies utilizing the kind of strategy should possess professional environmental expertise, and integrate specific relevant green activities, such as green design, green procurement to improve current processes, product developments. As a result, the innovation-based strategy forced companies to invest more resources and cultivate innovative capabilities to green managements

(4) closed-loop strategy: it is the most complicated type of GSCM strategy, and it linked the environmental performance to the entire supply chain activities. In other words, it required the more players in the supply chains involved more. For the simplest form in the closed-loop strategy, reverse logistics, it should take back materials produced from any production processes and end-of-life products, and disposed of them in various methods relied on complex degree of this type of strategy. However, it is difficult for manufacturers to track all of the products distributed from factories due to too many channels. Besides, the amount of return goods also accumulated enough to create economic scale. For these reasons, companies implementing the type of strategy successfully could incorporate efficiently economic, operational and environmental performance as well. As the authors mentioned, it needs lots of efforts to integrate highly, cooperate with many parties, and develop quite specialized knowledge and technology.

Therefore, it is the final goal for those executing green managements completely.

\section{Research Methodology}

A set of criteria covering wide range of parameters is submitted in the form of table and opinion of expert is taken to select pertinent criteria for strategy selection in the context of XYZ Automobile Company. Apart from this an unstructured opinion is also sought. Cost being one of the most important parameters has been included in this analysis as the alternatives chosen are cost competitive and thus a detailed analysis is required to select one of them on the basis of comprehensive analysis of various other factors and ultimately the priorities obtained with ANP can be seen in the context of cost parameter and an appropriate decision can be taken. The priorities obtained from the ANP can be directly used in linear programming model as the coefficients in the objective function to get the required distribution of the demand among the strategy which can satisfy a set of constraints related to lead time, plant capacity etc.

\section{Analytical Network Process (ANP)}

ANP is a generalized form of the widely used multicriteria decision making technique of AHP [19]. ANP offers several advantages over other evaluation techniques such as data envelopment analysis (DEA), expert systems, goal programming etc. It is the most comprehensive frameworks available for group decisions that are in use today with the decision-maker. It is a process that allows one to include all the factors and criteria, tangible and intangible, those have bearing on making best decision. The Analytic Network Process allows both interaction and feedback within clusters of elements (inner dependence) and between clusters (outer dependence). Such feedback best captures the complex effects of interplay in corporate world, especially when risk and uncertainty are involved.

The ANP, developed by Saaty, provides a way to input judgments and measurements to derive ratio scale priorities for the distribution of influence among the factors and groups of factors in the decision. Because the process is based on deriving ratio scale measurements, it can be used to allocate resources according to their ratioscale priorities. The well-known decision framework, the Analytic Hierarchy Process (AHP) is a special case of the ANP. Both the AHP and the ANP derive ratio scale priorities for elements and clusters of elements by making paired comparisons of elements on a common property or criterion. Although many decision problems are best studied through the ANP, one may wish to compare the results obtained with it to those obtained using the AHP or any other decision approach with respect to the time it took to obtain the results, the effort involved in making the judgments, and the relevance and accuracy of the results.

ANP models have two parts: the first is a control hierarchy or network of objectives and criteria that control the interactions in the system under study; the second are the many sub-networks of influences among the elements and clusters of the problem, one for each control criterion. The ANP has been applied to a large variety of decisions: marketing, medical, political, social, and forecasting and prediction and many others. Its accuracy of prediction is impressive in applications that have been made to economic trends, sports and other events for which the outcome later became known.

The ANP utilizes the idea of a control hierarchy or a control network to deal with different criteria, eventually leading to the analysis of benefits, opportunities, costs, and risks. By relying on control elements, the ANP parallels what the human brain does in combining different sense data as for example does the thalamus.

Software - SUPER DECISIONS is available for solving ANP problem and is used in this project. 


\section{Proposed Model and Approach}

In this section, we introduce an ANP model and its development to show how ANP can be used in the existing environment. It is acknowledged that each organization will have its own set of criteria and that the model for a particular enterprise may use other levels and criteria. Our attempt here is to present a generalized model based on factors and criteria mentioned from the literature that could then be adapted or extended to support a particular situation or organization.

\section{A. Case Study}

With the numbers of green programs was increasing; it was more difficult for the company to ensure the performances of them. Therefore, the top management should consider carefully which type of green management perspective they had, and assessed the importance of every factor in each green business activity objectively. In sum, they should choose an adequate GSCM strategy to guide all of the employees to strive to upgrade the overall environmental performances. For above the reasons, we targeted the key managers related the green programs of the case company and other experts in other companies with green programs to establish the ANP network and assist the XYZ company to confirm the best GSCM strategy. The company manufactures tractors and machine tools for the inland and outland delivery both. At the time of the model, the company was trying to decide between two development options to address the demand of the marketplace. The options were to develop a new strategy system or upgrade the speed of a current system. While the new system offered the potential for better performance, this had to be offset against the risks and costs involved with developing the technology necessary for its development. Due to funding and resource constraints, only one option could be pursued. Once a decision was made, the company was committed to pursuing that course of action. The decision was strategic in that the success of the development would bear greatly on the continued competitiveness of the company. In the following section, we will propose the ANP model and take the XYZ Company to be an example to explain a company how to apply the model to choose the appropriate GSCM strategy.

\section{B. Decision Model}

The first step is to construct a model to be evaluated. This example uses the factors discussed earlier to develop a model that explicitly considers many of the strategy selection issues found in literature and practice. The model is summarized in Fig. 1. The relevant criteria and alternatives are structured in the form of a hierarchy. More "strategic" decisions are shown higher in the hierarchy. The topmost elements are decomposed into subcomponents and attributes. The model development requires the development of attributes at each level and a definition of their relationships. In this example, the only interdependence or feedback occurs between all of the actors (or stakeholders) in the decision and all phases of the project as shown by the two headed arrow. The other single arrows indicate a one-way relationship.

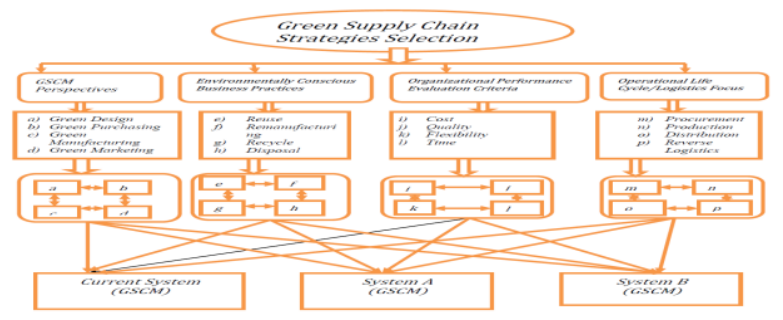

Figure 1. ANP model for Green supply chain strategy selection

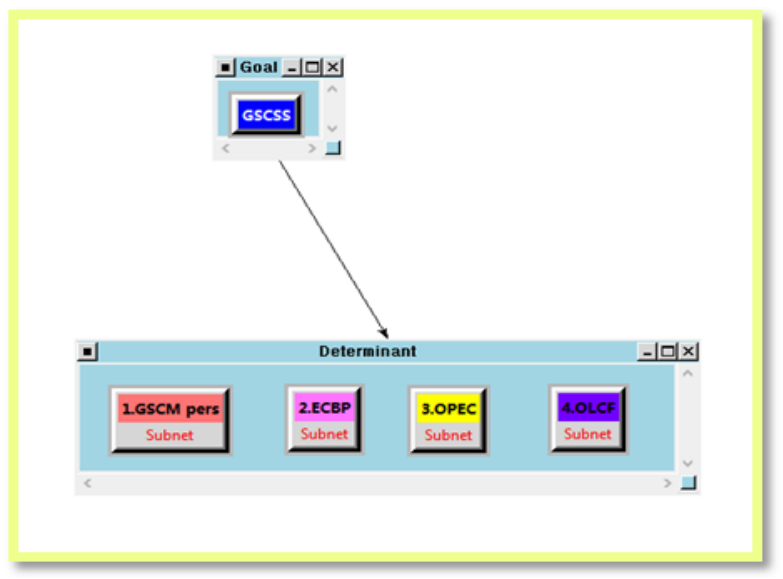

Figure 2.

\section{ANP Implementation Procedure}

Step 1 Formation of network with goal, clusters and subnets: The problem is first designed in the software by making clusters and the corresponding nodes and connections. The strategy selection problem is designed as hierarchical network with the goal as the topmost cluster. This is linked to another cluster containing Green supply chain perspective, environmentally conscious business practice; overall performance evaluation criteria and operational life cycle logistic focus as its nodes (fig. 2).

Step 2 the clusters and nodes under all 4 subnets, each subnet consists of two clusters i.e. Attributes and Alternatives.

Step 3 Node Comparisons: This involves comparison of nodes with respect to a control criterion.

Step 4 Generation of weighted and limiting super-matrix: In this step the generation of the weighted and the limiting super-matrices for all the four sub networks.

Step 5 The Values obtained at the subnet level are raised to the goal level and limit matrix (fig. 3) is obtained for goal.

Step 6: The values obtained from the synthesis are taken at the level of the goal and overall synthesis for the model is achieved as shown in Figure 4. 
Step7 Sensitivity analysis: In this the variations in the priority of the alternatives with respect to change in the weight age of the control criteria can be observed. One such graph is presented in figure 5 to show the variations in the priorities of the alternative with respect to business criteria.

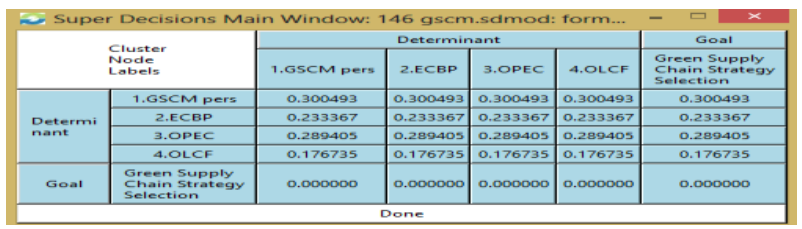

Figure 3.

\section{A. Result of ANP modelling}

Based on the priorities obtained from ANP, system A has highest priority coefficient of 0.5488 followed by system $\mathrm{B}$ and current system with 0.3237 and 0.1274 . Clearly system A is best choice. The results are indicators of the personal preferences which the Analysts have as the pairwise based on the response of experts on the attributes following hierarchy has been formed and used in ANP software - SUPER DECISIONS.

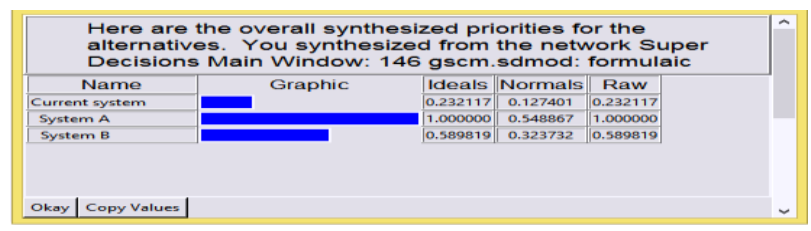

Figure 4.

Comparison (See in appendix A) is based on his knowledge, word of mouth information available to him and judgments. One of reasons could be the first hand experience of the present strategy system, which the analysts have in comparison to the here-say, and written details of other two alternatives.

\section{Conclusions}

In the current scenario of global operating conditions and competitive environment, it has become highly necessary for organizations to select the effective strategy. Any inaccurate selection of strategy will affect the company's overall performance. This shows that strategy selection procedure is a highly essential decision making process for companies. As discussed in the literature review, comprehensive research is done in attempt to arrive at systematic framework for strategy evaluation and selection. This paper is an endeavor to utilize ANP for ranking the potential strategy system and making the final selection. This method is applied to an automotive components manufacturing industry, considering 3 potential strategy system namely, current system, system A and system B. ANP method is solved using Super Decision package. In this method, benefits, opportunities, costs and risks factors are considered separately and weight age for each merit is provided basing on the company's strategic policies.

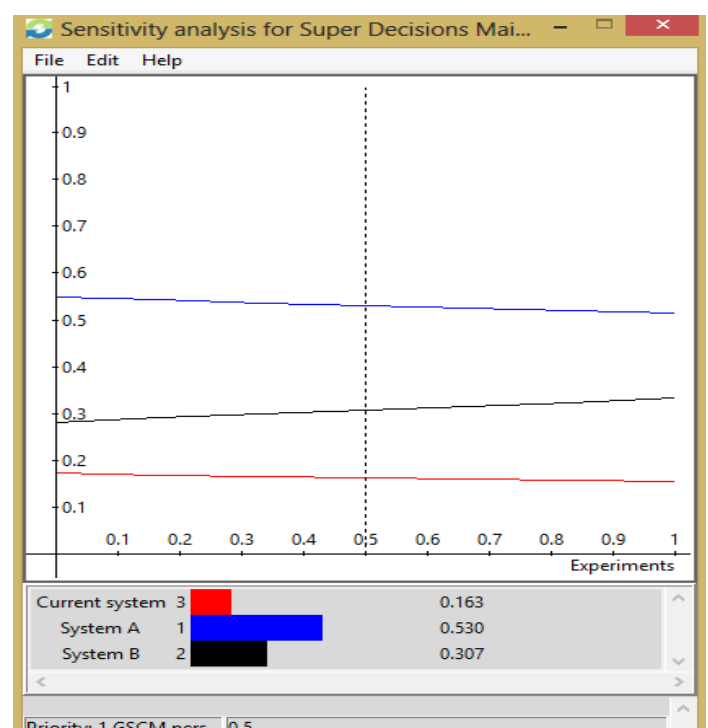

Figure 5.

\section{References}

1. Arvind Jayant, M.S.Dhillon (2014) "Use of Analytic Hierarchy Process (AHP) to Select Welding Process in High Pressure Vessel Manufacturing Environment" International Journal of Applied Engineering Research, Volume 10(8) 2015 pp.586595.

2. Arvind Jayant, M.Khan (2014) "TOPSIS-AHP Based Approach for Selection of Reverse Logistics Service Provider: A Case Study of Mobile Phone Industry" Procedia Engineering (Elsevier Publications), Vo.97, pp 2147-2156

3. Virender Paul and Arvind Jayant (2014), “Analytical Network Process (ANP) in Selection of Green Supplier: A Case Study of Automotive Industry" International Scientific Journal on Science Engineering \& Technology, Volume 17, No. 05, pp 453-465.

4. Priya Singh, Arvind Jayant (2015) "Selection of FMS: A Synthesis of 3MCDM Approaches" Journal of Material Science and Mechanical Engineering (JMSME), Volume 2(8), pp 15-20.

5. Veepan Kumar, Arvind Jayant (2015) "Use of AHP to Evaluate Supply Chain Collaboration in Competitive Business Environment" Journal of Material Science and Mechanical Engineering (JMSME), Volume 2(8), pp 15-20.

6. Arvind Jayant (2015) "Evaluation of EOL/Used cell phones management \& disposal alternatives: An ANP and balanced score card approach" International Journal of Waste Resources (IJWR), Volume 5, Issue 2

7. Arvind Jayant,A.Singh, and V.Patel (2011), "An AHP Based Approach for Supplier Evaluation and Selection in Supply Chain Management" International Journal of Advanced Manufacturing Systems, Volume 2, No. 1, pp. 1-6

8. Arvind Jayant (2011). "An Application of Analytic Network Process to Evaluate Supply Chain Logistics 
Strategies", International Journal of Analytic Hierarchy Process (USA). Vol.4, Issue 1.pp149-163.

9. Chen, shih, wu, shur(2006)-Using ANP for the selection of green supply chain management strategies 47(4)pp;18-20

10. Choudhary, M., \& Seth, N. (2011). Integration of green practices in supply chain environment- The practices of inbound, operational, outbound and reverse logistics. International Journal of Engineering Science and Technology, 3(6), 49954993. ISSN: 0975-5462

11. Diabat, A., \& Govindan, K. (2011).An analysis of the drivers affecting the implementation of green supply chain management. Resources Conservation and Recycling, 55(6), 659-667.

12. L. Meade and J. Sarkis, "Strategic analysis of logistics and supply chain management systems", Transpn Res.-E (Logistics and Transpn Rev.), Vol. 34, No. 3, pp. 201-215, 1998

13. Luthra, S., Kumar, V., Kumar, S., \& Haleem, A. (2011). Barriers to implement green supply chain management in automobile industry using interpretive structural modeling technique An Indian perspective. Journal of Industrial Engineering and Management, 4(2), 231-257.

14. Mudgal, R.K., Shankar, R., Talib, P., \& Raj, T. (2010). Modeling the barriers of green supply chain practices: An Indian perspective. International Journal of Logistics Systems and Management, 7(1), 81-107.

15. Olugu, E.U., Wong, K.Y., \& Shaharoun, A.M. (2011). Development of key performance measures for the automobile green supply chain. Resources, Conservation and Recycling, 55(6), 567-579.

16. Sarkis, J., Hasan, M.A., \& Shankar, R. (2007). Evaluating environmentally conscious manufacturing barriers with Interpretive Structural Modeling.

17. Saaty, T.L. (1980). The Analytic Hierarchy Process. New York: McGraw-Hill Book Co.

\section{Appendix A:}

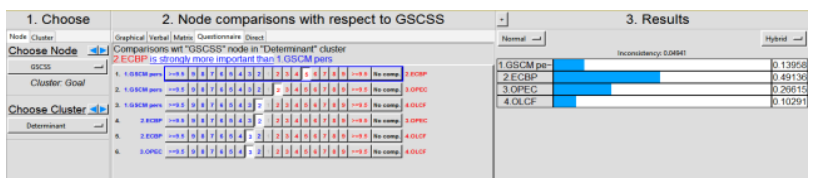

1) Pair-wise comparison of the dimensions

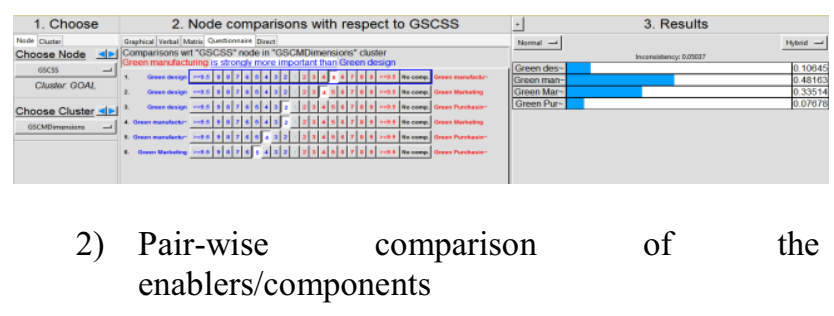

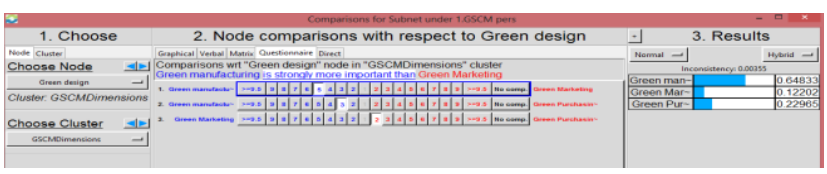

3) Pair wise comparison for the interdependencies

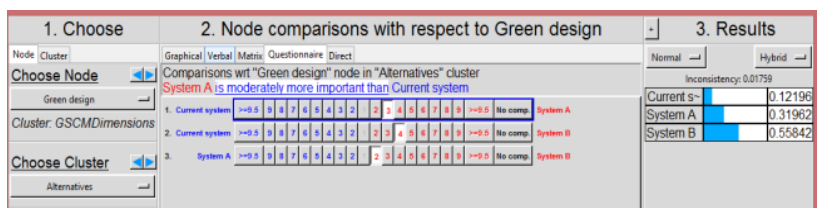

4) Pair wise comparison for the alternatives 